\title{
OPTIMIZATION OF BIODIESEL PRODUCTION PROCESS FOR HOMOGENEOUS CATALYSIS FROM USED COOKING OIL
}

\author{
C. Guerrero ${ }^{1}$ J. Parra ${ }^{2}$ and F. Sierra ${ }^{3}$ \\ ${ }^{1}$, Chemical Engineering and Mechanical, Master in Environmental Engineering $\mathrm{PhD}$ in Chemical Engineering. \\ Associate Professor, Universidad Nacional de Colombia. \\ caguerrerofa@unal.edu.co \\ ${ }^{2}$ Chemical Engineering (C), Universidad Nacional de Colombia \\ jojparrasa@unal.edu.co
}

${ }^{3}$ Doctor of Engineering, Universidad de Kassel. Associate Professor, Universidad Nacional de Colombia. fesierrav@unal.edu.co

\begin{abstract}
It is well known that the used cooking oil (UCO) is responsible for the high pollution found in groundwater, fact that leads to increase treatment cost of wastewater, moreover, the environmental problems produced by the use of diesel fuel increase the need of seeking alternatives to decrease this problems by means of the reuse of UCO, finding a cleaner alternative fuel. Biofuel such as biodiesel is considered as one of this alternative having environmental advantage due to decrease of pollutant emissions in diesel engines. Biodiesel from UCO is produced throughout the transesterification reaction, using alcohol and a catalyst. This paper reports the effect of temperature, alcohol/oil molar ratio, and catalyst amount used over the yield of the transesterification reaction using oil from hotel industry. The homogeneous catalysts was based in $\mathrm{NaOH}$ from 0.5 and $0.7 \%$ by weight, the range operation temperatures were between 50 and $60{ }^{\circ} \mathrm{C}$, with molar ratio alcohol / oil 6/1 and 9/1. Quite high yield values were shown, among 83 and $95 \%$, with a statistical error of less than 0.5.
\end{abstract}

\section{Key words}

Biodiesel, Used Cooking Oil, Transesterification, Fatty acids, renewable energy

\section{Introduction}

At present the energy needs of the human being on the rise, largely due to population growth and the steady depletion of major energy sources available without possibility of recover them, has raised questions about the development of new renewable energy sources to avoid a depletion at future and levelling its price in the market, besides being more environmentally friendly and generate energy safety of countries assuring forward an almost total decreased of their external dependence. Although there are already cleaner production methods that do not generate greenhouse gas emissions, for most activities taking place every day turn out to be inefficient because the size of the generators is huge compared to the small amount of energy generates. While these energy production methods can be perfected to be used effectively in all contexts, it is necessary improve the most used sources that exist, within which the biofuels production have become very important in recent years.

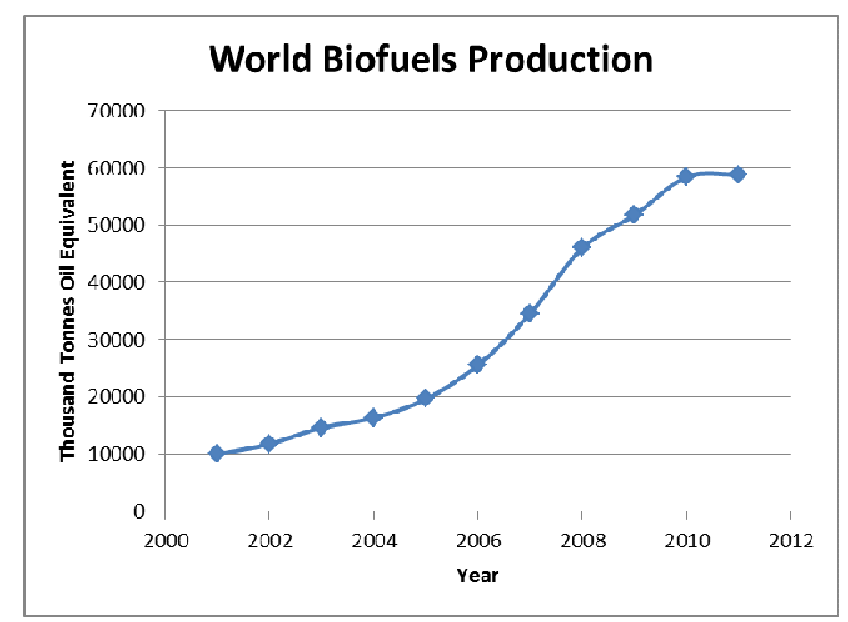

Figure 1. World Biofuel production

Fig 1 shows the development of biodiesel production right through the last years. An exponential increase occurs during the first few years, while for the years after 2008 , there was a stabilization, and yet none of these periods is presented a peaking. this is the main evidence that shows how biofuels have been replacing effectively use tradionales energy sources derived from petroleum.

However, the use of food as a raw material has generated a considerable number of drawbacks, mainly with environmental groups, due to those considered that is 
being used wrongly for the biodiesel production when it could be used for human consumption, which one way or another tends to raise prices in the market.

For this reason it is of great importance getting handle all those raw materials that today are being used, not in its pure state, but taking them after losing all useful as food to humans. At this point the optimization of treatment and subsequent biodiesel production from used cooking oils proves crucial in the current scenario to solve not only the energetic problem but also to reduce the opposition of the people in these new ways of production.

\section{Raw material}

Used cooking oil was recollected by hotel sector, this oil was characterized (determination of physic properties like viscosity or density) to determinate the pretreatment necessary to obtain an optimal raw material to transesterification process.

Physicochemical characteristics of the UCO used as raw material to biodiesel production are showed in Table 1. This table shows the main factors that define the treatment to adjust the waste oil according to the features necessary for carry out the transesterification reaction.

Table 1. Chemical characterization from used cooking oil

\begin{tabular}{|l|c|}
\hline \multicolumn{1}{|c|}{ Characteristics } & Value \\
\hline Acidity (\%) & 0.56 \\
\hline Moisture $37^{\circ} \mathrm{C}$ \\
\hline $\begin{array}{l}\text { Viscosity at } \\
\text { centistokes) }\end{array}$ & 0.25 \\
\hline Iodine value $\left(\mathrm{Cgl}_{2} / \mathrm{g}\right)$ & 44.78 \\
\hline $\begin{array}{l}\text { Peroxide value (meq. active } \\
\text { oxygen/Kg) }\end{array}$ & 108.22 \\
\hline Unsaponifiable matter $(\%)$ & 1.70 \\
\hline Saponification $(\mathrm{mg} \mathrm{KOH} / \mathrm{g})$ & 195.87 \\
\hline Ash (\%) & 0.030 \\
\hline Refractive index $25^{\circ} \mathrm{C}$ & 1.4700 \\
\hline Density $15^{\circ} \mathrm{C}(\mathrm{g} / \mathrm{ml})$ & 0.9216 \\
\hline Lovibond color & $16.3 * 70.0^{*} 0.0$ \\
\hline
\end{tabular}

According to data shown in table 1 the raw material oil present an acidity value of $1.5 \%$, for this value the test is executed without needing of esterification process, and no soap formations. By the other side peroxide index drop a result of more than 5 meq units of oxygen, this value represent decomposition and rotting; due to long time storing the large unsaturated carbonated chains are oxidized by the oxygen this is resulting in peroxide formation. The obtained value can be considerate outside of the established limits for pure oils; so we can expect that obtained biodiesel from this oil exhibit a resistance and adequate performance at low temperatures.

Used cooking oil which required a pretreatment to remove solid particles accumulated in the edible oil frying process. Humidity, peroxide index and acidity give us an idea to make our entire test; this methodology was used to be used for the missing test prior to transesterification.

Until now we can surely established that the ability of low temperatures performance of biodiesel it's high so in can be used as an possible alternative in the replacing of another energy kinds specially in the places where working temperatures are lower than the usual temperatures. Table 3 also the weighting average amont of abundant fatty acids in the test made for the oil used previously on figure 2.The results show a high correlativity with literature reported data, where oleic acid percentage is near the $30 \%$, this shows the proportion is higher that other fatty acids followed by palmitic and linoleic respectively.

\section{Experimental design}

Used Coking Oil (UCO) was recollected by hotel sector, this oil has special characteristics compared with edible cooking oil, its color is dark black, the density is lower than the edible oil and there is the presence of leftover particles of processed foods.

In the other hand, biodiesel production is developed by transesterification reaction, a typical reaction of lipids in which fatty acids derived from triglycerides react with an alcohol to obtain as a result esters. To produce an effective and satisfactory reaction is necessary that the raw material is free of impurities, but also in an experimental development carried out to determine the effect of each factor on the reaction yield, among these factors we not taken into account the purity level of the oil, because it is known beforehand that the best results 
are obtained with a higher level of purity, and therefore be carried out all experiments with the same level of purity.

Factors to design the experimental process were selected based on externally generated changes that could affect somehow the internal reaction. Based on this, selected factors were: molar ratio between alcohol and oil, percentage of catalyst, temperature and washing agent. After that, it was established that the experimental design to use is factorial type with a $2^{\mathrm{k}}$ form, two levels (high and low) for $\mathrm{k}$ variables. Table 2 contains the value for each level in each defined variable above; these were defined according to review papers which determine a range of values as the best conditions for transesterification process.

Table 2. Value for design variables

\begin{tabular}{|c|c|c|}
\hline Design variable & Low Level & High Level \\
\hline Molar ratio alcohol/oil & $6 / \mathrm{I}$ & $9 / 1$ \\
\hline Percentage of catalyst & 0.5 & 0.7 \\
\hline Temperature $\left({ }^{\circ} \mathrm{C}\right)$ & 50 & 60 \\
\hline Washing agent & Water & $\begin{array}{c}\text { Acetic } \\
\text { acid }\end{array}$ \\
& & \\
\hline
\end{tabular}

Molar ratio was defined in a range between 6/1 and 9/1, it is due to for a lower ratio the transesterification process is not carried out completely, and for a higher ratio the separation of methyl ester from glycerin is harder. A similar analysis for temperature shows that for high values, the oil is burned and yield decreases, also seen the appearance of ashes; finally for select the percentage of catalyst used, was taken into account that a high proportion of it produces alone a loss of material because the yield remains the same, therefore were reviewed values commonly used in the literature for the $\mathrm{NaOH}$.

Table 3. Experiments run to check the effect of each selected variable in the transesterification process

\begin{tabular}{|c|c|c|c|c|c|}
\hline No & Code & $\begin{array}{c}\text { Molar } \\
\text { ratio }\end{array}$ & $\begin{array}{c}\% \\
\text { Catalyst }\end{array}$ & $\begin{array}{c}\text { Temperature } \\
\left({ }^{\circ} \mathbf{C}\right)\end{array}$ & $\begin{array}{c}\text { Washing } \\
\text { agent }\end{array}$ \\
\hline I & 1111 & $6 / I$ & 0.5 & 50 & Acetic Ac \\
\hline 2 & 11112 & $6 / I$ & 0.5 & 50 & Water \\
\hline 3 & 1121 & $6 / I$ & 0.5 & 60 & Acetic Ac \\
\hline 4 & 1122 & $6 / I$ & 0.5 & 60 & Water \\
\hline 5 & 1211 & $6 / I$ & 0.7 & 50 & Acetic Ac \\
\hline 6 & 1212 & $6 / 1$ & 0.7 & 50 & Water \\
\hline 7 & 1221 & $6 / 1$ & 0.7 & 60 & Acetic Ac \\
\hline 8 & 1222 & $6 / 1$ & 0.7 & 60 & Water \\
\hline 9 & 21111 & $9 / 1$ & 0.5 & 50 & Acetic Ac \\
\hline 10 & 2112 & $9 / 1$ & 0.5 & 50 & Water \\
\hline 11 & 2121 & $9 / 1$ & 0.5 & 60 & Acetic Ac \\
\hline 12 & 2122 & $9 / 1$ & 0.5 & 60 & Water \\
\hline 13 & 2211 & $9 / 1$ & 0.7 & 50 & Acetic Ac \\
\hline 14 & 2212 & $9 / 1$ & 0.7 & 50 & Water \\
\hline
\end{tabular}

\begin{tabular}{|c|c|c|c|c|c|}
\hline 15 & 2221 & $9 / 1$ & 0.7 & 60 & Acetic Ac \\
\hline 16 & 2222 & $9 / 1$ & 0.7 & 60 & Water \\
\hline
\end{tabular}

For the selected experimental design, in factorial type $2^{\mathrm{k}}$, and a total of four variables are necessary execute sixteen experiments, it is due to all the variables all variables interact with each other. Table 3 shows the values of each variable in each experimental design. Here the code selected is composed by three number where in order represent molar ratio alcohol/oil, percentage of catalyst, temperature and washing agent, (1) represent low level and (2) high level; also for each one is carry out a duplicated to obtain a total of thirty two experimental processes.

After carrying out the entire experimental process, were executed a series of calculations taking into account the composition of the oil to obtain an effective molar comparison between fatty acids that entered to the transesterification process and the methyl esters obtained at the end of it. A simple relation between these two quantities was insufficient to determine which amount of the oil used had reacted, and thus known the yield obtained in each experimental process with the values shown in Table 3, due to each experimental process was executed twice to support the result obtained; according to it "Yield 1" refers to the original process and "Yield 2" refers to a replica of this.

Table 4. Yield obtained for each experimental process

\begin{tabular}{|c|c|c|c|}
\hline No & Code & Yield I & Yield 2 \\
\hline$I$ & $I I I I$ & 82.499 & 94.196 \\
\hline 2 & $I I I I$ & 81.897 & $94.17 I$ \\
\hline 3 & $I I 2 I$ & 95.185 & 94.707 \\
\hline 4 & $I I 22$ & 94.577 & 94.598 \\
\hline 5 & $I 2 I I$ & 93.092 & 91.342 \\
\hline 6 & 1212 & 95.395 & 91.552 \\
\hline 7 & $122 I$ & 87.407 & 90.048 \\
\hline 8 & 1222 & 87.762 & 83.59 \\
\hline 9 & $21 I I$ & 85.633 & 94.329 \\
\hline 10 & 2112 & 94.282 & $92.7 I$ \\
\hline$I I$ & 2121 & 95.957 & 93.055 \\
\hline 12 & 2122 & 95.395 & 81.552 \\
\hline 13 & $221 I$ & 91.88 & 94.246 \\
\hline 14 & 2212 & 95.203 & 94.307 \\
\hline 15 & $222 I$ & 89.873 & 90.36 \\
\hline 16 & 2222 & 95.879 & 90.118 \\
\hline
\end{tabular}

\section{Data Statistical Analysis}

Now, obtained each yields is possible to make an overall comparison of all results to observe how it affects each 
variables to the transesterification reaction. To analyze each parameter selected as a continuous range rather than two separate values, was used an experimental design tool called "Design Expert". The design parameters were introduced as a continuous numeric variable, except washing agent which is a categorical variable. Alcohol/oil molar ratio was the only adimensional variable. Temperature is given in Celsius degrees and catalyst percentage was calculated over total weight. Table 5 shows an overview obtained to each sample in the experimentation. Here was introduced the yield for two duplicates, yield 1 corresponds to original procedure and yield 2 is for second run of the experiment. The results obtained when carrying out this analysis are presented in Table 5 .

Table5. Results obtained from each experimental duplicate

\begin{tabular}{|c|c|c|c|c|c|c|c|c|}
\hline 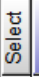 & Std & Run & $\begin{array}{c}\text { Factor } 1 \\
\text { A:Moles alco... }\end{array}$ & $\begin{array}{c}\text { Factor } 2 \\
\text { B:\% Catalyst } \\
\%\end{array}$ & \begin{tabular}{|c|} 
Factor 3 \\
C: Temperature \\
${ }^{\circ} \mathrm{C}$ \\
\end{tabular} & $\begin{array}{c}\text { Factor } 4 \\
\text { D:Washing A... }\end{array}$ & $\begin{array}{c}\text { Response } 1 \\
\text { Yield } 1 \\
\%\end{array}$ & $\begin{array}{c}\text { Response } 2 \\
\text { Yield } 2 \\
\%\end{array}$ \\
\hline- & 10 & 1 & 9.00 & 0.50 & 50.00 & Water & 94.282 & 92.71 \\
\hline & 2 & 2 & 9.00 & 0.50 & 50.00 & Acetic Acid & 85.633 & 94.329 \\
\hline & 14 & 3 & 9.00 & 0.50 & 60.00 & Water & 95.395 & 81.552 \\
\hline & 13 & 4 & 6.00 & 0.50 & 60.00 & Water & 94.577 & 94.598 \\
\hline & 16 & 5 & 9.00 & 0.70 & 60.00 & Water & 95.879 & 90.118 \\
\hline & 12 & 6 & 9.00 & 0.70 & 50.00 & Water & 95.203 & 94.307 \\
\hline & 8 & 7 & 9.00 & 0.70 & 60.00 & Acetic Acid & 89.873 & 90.36 \\
\hline & 5 & 8 & 6.00 & 0.50 & 60.00 & Acetic Acid & 95.185 & 94.707 \\
\hline & 7 & 9 & 6.00 & 0.70 & 60.00 & Acetic Acid & 87.407 & 90.048 \\
\hline & 11 & 10 & 6.00 & 0.70 & 50.00 & Water & 95.395 & 91.552 \\
\hline & 3 & 11 & 6.00 & 0.70 & 50.00 & Acetic Acid & 93.092 & 91.342 \\
\hline & 6 & 12 & 9.00 & 0.50 & 60.00 & Acetic Acid & 95.957 & 93.055 \\
\hline & 4 & 13 & 9.00 & 0.70 & 50.00 & Acetic Acid & 91.88 & 94.246 \\
\hline & 1 & 14 & 6.00 & 0.50 & 50.00 & Acetic Acid & 82.499 & 94.196 \\
\hline & 9 & 15 & 6.00 & 0.50 & 50.00 & Water & 81.897 & 94.171 \\
\hline & 15 & 16 & 6.00 & 0.70 & 60.00 & Water & 87.762 & 83.59 \\
\hline
\end{tabular}

First, it can be seen that by keeping all the conditions constant while varying the molar ratio have a similar range of values, this may suggest that yield obtained for this interval is independent of the amount of alcohol used, that is while working in this range, the yield is always the same; it is, according to figure 2, for similar values of variables changing alone the molar ratio, was obtained a similar yield, this means that for equal operating condition, to a molar ratio between $6 / 1$ and $9 / 1$, the yield is similar, so for these values, quantity of methanol is not a significant variable to biodiesel production.

All yields data obtained were processed and finally was reached to establish a correlation between the three variables selected. With this, was possible develop a model used to generated a set of values that were taken as a basis for determining the error of the developed experimental model. This is used to calculate in a general way the obtained results according to how accurate the model used and thus determine if it is necessary to perform a statistical transformation to the model.

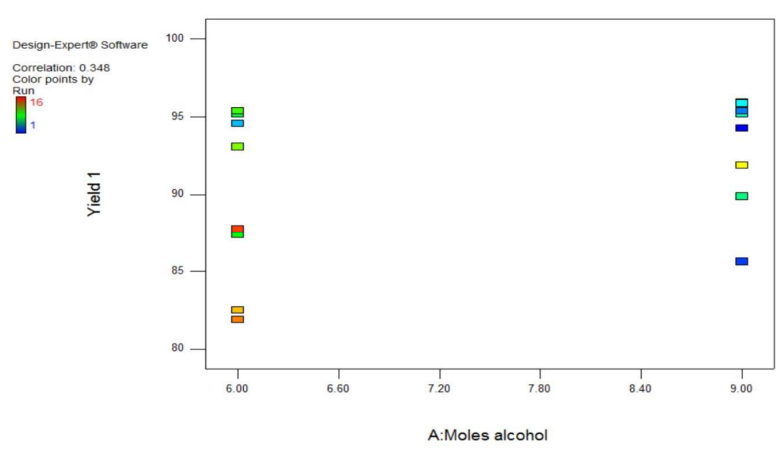

Figure 2. Yields organization according to molar ratio of alcohol / oil

Figure 3 shows the relative standard errors of average prediction, using a standard deviation of 1 is calculated relative prediction error. Most data has an error lower than 0.5 , and very few of them exceed this value. So, this indicate that majority of obtained data is near to ideal line of calculated statistic design. The numerical mean error obtained for this experimental process is kept within the limits suggested by the design, therefore the obtained approximation to the behavior of the system can be considered correct.

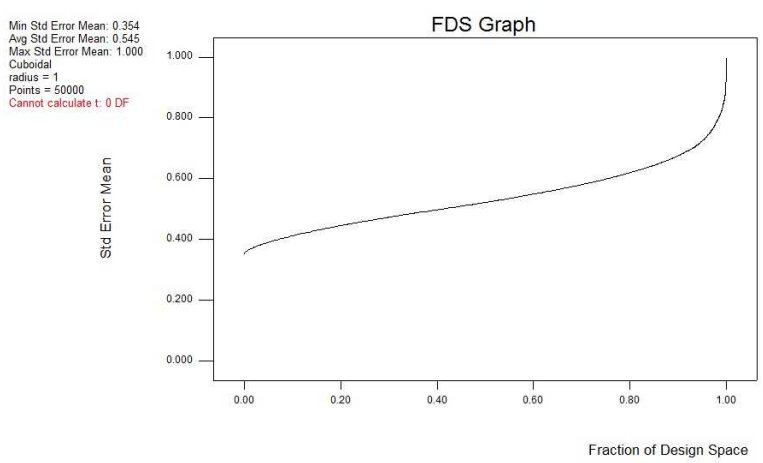

Figure 3. Error mean for experimental design

The perturbation plot is used to compare the effect of all the factors for a specific point in the design space. Figure 4 shows the behavior of the designed model when is used the central point of each variable, it is for a temperature of $55^{\circ} \mathrm{C}, 0.6 \%$ wt catalyst and 7.5 for molar ratio. A steep slope for the variables shows that these factors modify in a large degree the result obtained; for extreme values of each variable the slope increase and it is due to a higher dependence of yield in function of these parameters.

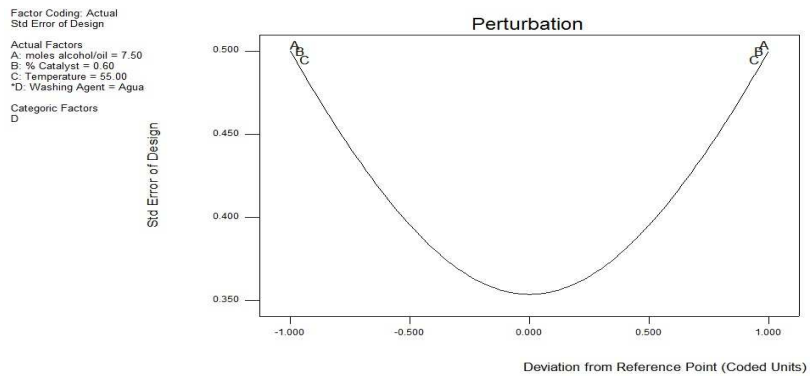

Figure 4. Perturbation caused by each factor in the design 
Figure 5 shows a three dimensional graph of the yield obtained with respect to temperature and percentage of catalyst used while varying the ratio between alcohol and oil. Although the slope of the graph tends to zero, during the study of the obtained data protruding points were visualized in which yield takes minimum or maximum values. These points are important because they help to select the best operating conditions for optimum results while taking into account the amount of energy or raw materials needed to achieve this yield.

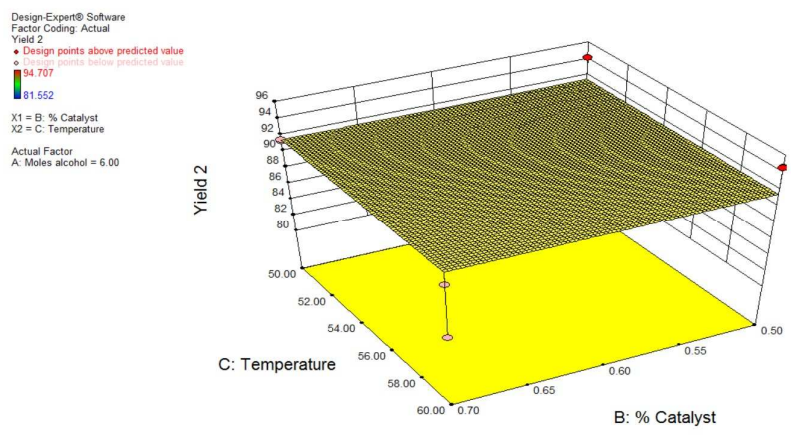

Figure 5. Yield surface for temperature and \% catalyst

We can see that in the collected information the yield is almost completely independent of the washing agent used, this is due to it is not involved in the reaction, but rather it is used to purify the amount of biodiesel already obtained. In the other hand similar yields were obtained for both amounts of alcohol used, and due to this is one of the most expensive raw materials, based on this we can choose the value for the other variables; therefore to select a ratio of 6-1 only remains to define the temperature and amount of catalyst used.

The higher values of yield for this relation alcohol/oil were found for $0.5 \%$ of catalyst at $60{ }^{\circ} \mathrm{C}$ and $0.7 \%$ catalyst at $50^{\circ} \mathrm{C}$. Given that the cost of $\mathrm{NaOH}$ as catalyst to be used, it being low, due to the small amounts used and the difference between the two alternatives is only $0.2 \%$, while the cost of keeping $10^{\circ} \mathrm{C}$ over during the time of reaction appears to be more expensive, due to it we considered that the best option is to use $0.7 \%$ catalyst at a temperature of $50^{\circ} \mathrm{C}$.

\section{Conclusion}

The best balance between cost and performance is obtained for a molar ratio of 6 to 1 , using $0.7 \%$ catalyst and $50^{\circ} \mathrm{C}$. Probably it is not the best yield obtained, however not justified increase significantly the operating expenses for insignificant increase in yield.

Although these yield values were obtained at laboratory conditions, it is possible that this decrease in an industrialized process due to less interaction between raw materials and catalyst, however relations into the yields obtained are maintained, and therefore the chosen operating conditions will be who generate better results.

Completely replace fossil fuels with renewable alternatives is certainly the goal that in the next years should be achieved, however the current model is not the most effective because while trying to solve a problem we are increasingly the difficult to feed the world population, due to this satisfy both demands using as raw material in a process a residue of the other might become in the future the best option to discard completely the use of petroleum products.

\section{Acknowledgement}

Special gratitude to the research group: Energy recovery of natural resources - APRENA, Department of Chemistry from National University of Colombia for the contribution to this research.

\section{References}

[1] Agarwal M., Chauhan G., Chaurasia S, Singh K., Study of catalytic behavior of $\mathrm{KOH}$ as homogeneous and heterogeneous catalyst for biodiesel production, Malaviya National Institute of Technology, Department of Chemical Engineering, Jaipur, India, 2011

[2] Bezergianni S, Dimitriadis A, Kalogianni A, Pilavachi P, Hydrotreating of waste cooking oil for biodiesel production. Part I: Effect of temperature on product yields and heteroatom removal, Chemical Process Engineering Research Institute, 2010.

[3] Costa C, Martins A, Mata T, Morais S,Pinto G, Simulation and life cycle assessment of process design alternatives for biodiesel production from waste vegetable oils, Departamento de Engenharia Química, Instituto Superior de Engenharia do Porto (ISEP), 2010.

[4] Macario A., Giordano G., Onida B., Cocina D, Biodiesel production process by homogeneous/heterogeneous catalytic systemusing an acid-base catalyst, Department of Chemical Engineering \& Materials, Università della Calabria, Rende (CS), Italy, 2010. 